\title{
A comprehensive assessment of minimum quantity lubrication machining from quality, production, and sustainability perspectives
}

\author{
Nilanjan Banerjee, Abhay Sharma* \\ Indian Institute of Technology Hyderabad, Sangareddy, Hyderabad 205285, India
}

\section{A R T I C L E I N F O}

\section{Article history:}

Received 8 April 2018

Received in revised form 30 June 2018

Accepted 3 July 2018

\section{Keywords:}

Minimum quantity lubrication

Metaheuristic optimization

Quality

Environmental friendly machining

Sustainable manufacturing

\begin{abstract}
A B S T R A C T
The article presents minimum quantity lubrication (MQL) machining of Ti-6Al-4 V in a collective framework of multiple objectives - quality (surface roughness), environmental friendliness (specific cutting energy, tool wear, and oil consumption), and production (material removal rate and tool wear). In one of the first of its kind, the proposed approach uses cutting fluid parameters (oil quantity in the oil+air mixture, air pressure, and proportion of oil at the rake and flank face) along with machining parameters in multi-objective meta-heuristic optimization. The investigation reveals that the three objectives are distinct functions of process inputs. Thus, focus on one of the objectives - quality, production, and environmental aspects - hampers the others. A reasonable balance between the three aspects can be achieved through simultaneous optimization. Precise control over cutting fluid parameters, especially the oil proportion at rake and flank face, is a major factor that helps in improving environmental friendliness and productivity. The findings of the investigation will be useful for preparing a guideline for simultaneous selection of machining and cutting fluid parameters for economic and environmental viable manufacture of quality products.
\end{abstract}

(c) 2018 Elsevier B.V. All rights reserved.

\section{Introduction}

Minimum quantity lubrication (MQL) has evolved as an alternative to wet machining in many tool and workpiece combination scenarios. Lower consumption of cutting fluids results in reduced occupational health hazards on the shop floor, without compromising the machined surface quality [8]. This has made MQL an environmentally friendly machining process [23]. With the constantly increasing demands of difficult-to-machine materials, such as titanium and nickel-based alloys, further improvements in this technique are required. When machining titanium alloys, heat is accumulated at the tool-workpiece interface because of lower thermal conductivity. Conventionally, machining of these alloys is done using a large amount of coolant. To successfully introduce MQL for the machining of titanium alloys, its effectiveness must be understood [4]. Several ambiguities in the MQL technique still exist, which limit its widespread use in industrial scenarios. For example, in a single-point metal cutting operation, as shown in Fig. 1, since the rake and flank faces of the tool, are most affected by heat, distributing the cutting fluid in proportion to heating at these two locations might be more beneficial compared to an individual supply at these two locations in equal proportion.

Vazquez et al. [27] have demonstrated the effectiveness of MQL in reducing tool wear and burr formation while micro milling Ti-6Al-4V

\footnotetext{
* Corresponding author.

E-mail address: abhay@iith.ac.in (A. Sharma).
}

alloy. These authors also found that the surface finish could be improved by adjusting the spraying direction of the MQL fluid, as well as reducing tool wear compared to conventional coolant application and dry machining. Compared to conventional flood coolant supply, localized cooling using a through-tool coolant supply has been reported more efficient in reducing the surface roughness. Specifically, focused cutting fluid can result in the more optimal usage of the cutting fluid; however, the location of the supply and the amount of oil in the aerosol are additional parameters that need to be controlled in MQL.

Recently, investigators have attempted to quantify the effects of operating parameters on the efficacy of the MQL process through process modeling and optimization. To obtain lower surface roughness, Simunovic et al. [25] used the response surface method to optimize the machining parameters of speed, feed, and depth of cut, as well as different cooling and lubricating conditions for a face-milling process. Shokoohi et al. [24] investigated the effectiveness of wet, dry, and minimum quantity cooling and lubrication machining on workpieces that were either pre-cooled or not. The power consumption and surface roughness were analyzed through regression models. Jiang et al. [10] developed an optimization model to reduce the cutting fluid consumption and process cost for a turning operation. The machining parameters (speed, feed, and depth of cut) were considered as process variables. Process cost was defined in terms of product operation cost and cutting tool cost, while the cutting fluid consumption was defined in terms of reusable cutting fluid and non-reusable cutting fluid. The multi-objective optimization model developed from this work was effective in 


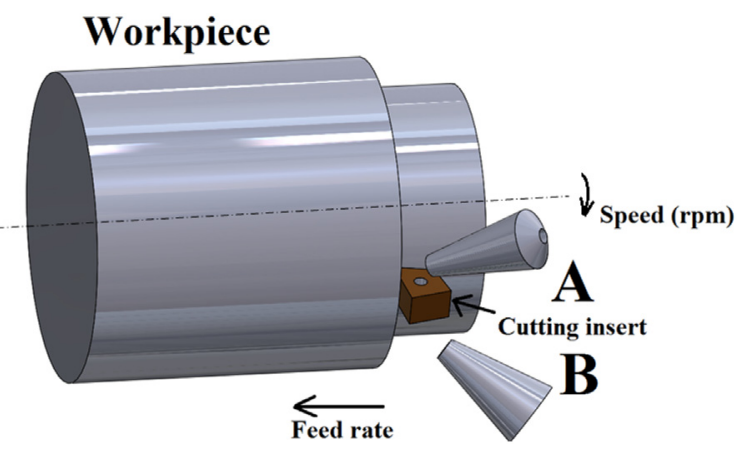

Fig. 1. Schematic representation of single point metal cutting operation with multiple nozzle $(A=$ Nozzle at the rake face; $B=$ Nozzle at the flank face).

reducing the consumption of cutting fluid by $17 \%$. Pusavec et al. [14] developed predictive models for surface roughness, cutting force, and tool wear, where cutting speed, feed rate, depth of cut, and different cooling and lubrication conditions were used as input variables. Coolant was mainly focused on the rake and flank face of the tool, either individually or in combination. When the MQL aerosol was supplied at the rake and flank face simultaneously, favorable surface integrity characteristics were achieved with lower power consumption. In a subsequent study [15], the developed models were further used to optimize process parameters for better tool life, surface quality, and lower power consumption. Davoodi and Tazehkandi [3] developed a regression model to show the effect of cutting speed and undeformed chip thickness on cutting force, feed force, and tool tip temperature. These authors found that the lowest undeformed chip thickness, when accompanied by the highest cutting speed, could result in lower cutting forces and tool tip temperature for dry machining condition; the performance was comparable to that of conventional wet machining. Liu et al. [12] used a coupled response surface design to analyze the effect of cutting speed, feed rate, and depth of cut on the cutting force and surface roughness under dry, wet, and MQL conditions. The effect of feed rate was more prominent on the surface roughness and cutting force, followed by cutting speed and depth of cut. MQL showed better performance compared to dry and wet machining. Saini et al. [17] optimized the effect of cutting speed, feed rate, and approach angle on main cutting force and tool tip temperature under dry and MQL conditions. Zhang et al. [28] optimized speed, feed, depth of cut, and lubrication conditions for environmentally friendly machining austenitic stainless steel with high efficiency and less energy consumption. [2] statistically analyzed the effect of MQL, compressed air cooling, and dry cutting on surface quality generated while milling magnesium alloy.

From the analysis of literature, it is observed that process modeling and optimization investigations regarding MQL have been conducted with a limited number of machining process parameters, with primary focus on the surface finish of the machined sample (e.g., $[3,5-7,9,11,12,16,18,19])$. Other objectives, such as specific cutting energy [7,11,12], flank wear [5], cutting forces [3,13], material removal rate [13], and power consumption [11], are rarely optimized. Few investigations have attempted to optimize MQL process for the productivity and cutting fluid consumption $[10,15]$. However, an environmentally friendly machining process should have lower energy consumption, lower material usage, and cutting fluid consumption. On the other hand, from the industrial point of view, a profitable production process should maximize the production rate (maximizing the material removal rate and simultaneously minimizing the tool wear, because tool wear leads to change in tool geometry that causes a delay in production). With new developments in MQL process, such as controlled supply of cutting fluid at localized places (e.g., rake and flank) [1]; MQL parameters, such as fluid supply rate, as well as its pressure and distribution at rake and flank faces, should be included in the process model, together with machining parameters (e.g., cutting speed, tool feed rate, and depth of cut). Moreover, process models for responses of various types, which represent quality, production rate, and environmentally friendliness, need to be developed.

The broader objective of this investigation is to present the underlying dynamics of MQL from quality, production rate, and environmentally friendliness perspectives, given the latest developments in the process. The investigation seeks to develop a new process model for responses such as surface roughness, specific cutting energy, oil consumption rate, tool wear, and material removal rate, as functions of MQL parameters, in addition to conventionally investigated machining parameters. Consequently, through selection and aggregation of appropriate process models, the article develops assessment approaches of the MQL process focused on quality, production or environmental friendliness. The aim is to evaluate the inherent system trade-offs that occur when the process is optimized from the individual perspectives of quality, production or environmentally friendliness and, thus, offer a guideline for parameter selection for better utilization of the process capability.

The following section presents a mathematical formulation of the problem under consideration. A detailed experimental investigation is presented next wherein machining parameters (i.e., cutting speed, depth of cut, and tool feed rate) along with MQL parameters (i.e., the proportion of oil at rake and flank face, amount of oil rate and pressure of aerosol) are varied following a design of experiments. The process outcomes, namely, surface roughness, cutting force (used for computing specific cutting energy), material removal rate, tool wear rate, and oil consumption rate, are recorded for machining of Ti-6Al- $4 \mathrm{~V}$ as a candidate material. Subsequently, development of process models and multi-objective optimization are presented, followed by a discussion on the results and conclusions.

\section{Mathematical formulation}

The MQL optimization problem under consideration is a multi-input multi-output (MIMO) system where there are $n$ input variables $(x)$ that affect the process responses. The quality objective $y$ can be defined as follows:

$y_{j}=f_{j}\left(x_{i}\right) \quad i=1, \ldots, n$ and $j=1, \ldots, m$

The MIMO system can be converted in to a multi-input single-output (MISO) system through aggregation of different responses that leads to

$\boldsymbol{Y}=\boldsymbol{A}\left(\boldsymbol{y}_{\boldsymbol{j}}\right)=\mathbf{g}\left(\boldsymbol{x}_{\boldsymbol{i}}\right)$

where $Y$ is an aggregate objective, $A$ is an aggregation function that eventually be expressed as $g$, a function of input $x_{i}$. The aggregate function, known as an aggregate index, developed by Swamee and Tyagi [26] and subsequently used by [21,22]) in the optimization of manufacturing problems, is used in the present investigation. The aggregate index is given as follows:

$\boldsymbol{Y}=\left(\mathbf{1}-\boldsymbol{m}+\sum_{j=1}^{\boldsymbol{m}} \boldsymbol{s}_{\boldsymbol{j}}^{-\frac{1}{\beta}}\right)^{-\beta}$

where ' $\beta$ ' is a positive constant. At $\beta=0.4$, the aggregation most satisfactorily overcomes the problem of 'ambiguity' and 'eclipsing'. $s_{j}$ are sub-indices that are responses normalized between 0 and 1 . If the response is expected to be 'higher-the-better', the sub-index is given as follows:

$s_{j}=\frac{y_{j}-y_{j}^{\min }}{y_{j}^{\text {max }}-y_{j}^{\text {min }}}$

where $y_{j}^{\max }$ and $y_{j}^{\min }$ represent the maximum and minimum value of $y_{j}$ over the total domain of process parameters, respectively. For the 
'lower-the-better' type of responses, the sub-index is given as:

$s_{j}=1-\frac{y_{j}-y_{j}^{\text {min }}}{y_{j}^{\text {max }}-y_{j}^{\text {min }}}$

In case of a constrained optimization, wherein an output feature is expected to be good in a lower to upper range between $y_{j}^{L}$ and $y_{j}^{U}$, respectively, the sub-index can be defined as:

$s_{j}=\left\{1-\frac{y_{j}-y_{j}^{L}}{y_{j}^{U}-y_{j}^{L}}, \quad y_{j}^{L} \leq y_{j} \leq y_{j}^{U} 0, \quad\right.$ else

The responses are clubbed as per optimization aspect (quality, production, and environmental), as shown in Table 1. A given aspect, while optimized, includes multi-responses, marked as $(\mathcal{V})$ (e.g., while optimizing the process from an environmental aspect, specific cutting energy, oil consumption rate, and tool wear rate are simultaneously minimized). Similarly, when the process is optimized from a production aspect, tool wear is minimized, and material removal rate is maximized. In addition to the three aspects, another aspect termed as 'all-inclusive' is considered, in which all the responses are optimized. This aspect tests the trade-offs that the system offers when the optimization exercise intends to achieve all of the responses simultaneously.

The five responses are surface roughness $(R a)$, specific cutting energy $(\mathrm{S})$, oil consumption rate $\left(O_{s}\right)$, tool wear $\left(T_{w}\right)$, and material removal rate $(M)$, and these are aggregated for optimization of quality, environmental, production, and all-inclusive aspects (Table 1). The material removal rate is the higher-the-better type and follows Eq. 4 for sub-index formation. The surface roughness is the better-in-a-range type and subindexed using Eq. 6. The remaining three responses are the lower-thebetter type and thus follow Eq. 5 for sub-indexing.

The definition of objective functions for the four aspects are given below:

$$
\begin{array}{ll}
\max & Y_{\text {Quality }}=\left(1-1+\sum_{j=1}^{1} s_{j}^{-\frac{1}{\beta}}\right)^{-\beta}=s_{1} \\
\max & Y_{\text {Enviornmental }}=\left(1-3+\sum_{j=2}^{4} s_{j}^{-\frac{1}{\beta}}\right)^{-\beta}=\left(-2+\sum_{j=2}^{4} s_{j}^{-\frac{1}{\beta}}\right)^{-\beta} \\
\max & Y_{\text {Production }}=\left(1-2+\sum_{j=3}^{5} s_{j}^{-\frac{1}{\beta}}\right)^{-\beta}=\left(-1+\sum_{j=3}^{5} s_{j}^{-\frac{1}{\beta}}\right)^{-\beta} \\
\max & Y_{\text {All-inclusive }}=\left(1-5+\sum_{j=1}^{5} s_{j}^{-\frac{1}{\beta}}\right)^{-\beta}=\left(-4+\sum_{j=1}^{5} s_{j}^{-\frac{1}{\beta}}\right)^{-\beta}
\end{array}
$$

subject to

$$
\left\{\begin{array}{l}
x_{i}{ }^{\min } \leq \mathrm{X}_{i} \leq \boldsymbol{x}_{i}{ }^{\max } \\
S, O_{s}, T, M \geq 0 \\
R_{a} \geq 0.0321 \frac{f_{\min }{ }^{2}}{r}(\text { one side constrained roughness for rough cut) } \\
0.0321 \frac{f^{2}}{r} \leq R_{a} \leq 2 \mu m \text { (both side constrained roughness for finish cut) }
\end{array}\right.
$$

where $f_{\min }$ is the minimum tool feed rate, and $r$ is the tool edge radius.

Table 1

Process Reponses and optimization aspects.

\begin{tabular}{llllll}
\hline$j$ & Response & Aspects & & & \\
\hline & & Quality & Environment & Production & All-inclusive \\
1 & Surface roughness $\left(R_{a}\right)$ & $\checkmark$ & $\mathbf{x}$ & $\mathbf{x}$ & $\checkmark$ \\
2 & Specific cutting energy $(S)$ & $\mathbf{x}$ & $\checkmark$ & $\mathbf{x}$ & $\checkmark$ \\
3 & Oil consumption rate $\left(O_{s}\right)$ & $\mathbf{x}$ & $\checkmark$ & $\mathbf{x}$ & $\checkmark$ \\
4 & Tool wear $\left(T_{w}\right)$ & $\mathbf{x}$ & $\checkmark$ & $\checkmark$ & $\checkmark$ \\
5 & Material removal rate $(M)$ & $\mathbf{x}$ & $\mathbf{x}$ & $\checkmark$ & $\checkmark$ \\
\hline
\end{tabular}

Two types of constraints on surface roughness are evaluated. The rough cuts are constrained from only one side by setting the lower limit as idle surface roughness (i.e., $\boldsymbol{R}_{\boldsymbol{a}}=\mathbf{0 . 0 3 2 1} \frac{\boldsymbol{f}_{\min ^{2}}}{\boldsymbol{r}}$ ) but the finish cut is also constrained by an upper limit specified in the product specifications (e.g., $2 \mu \mathrm{m}$ ). The sub-indices $\left(s_{j}\right)$ are functions of the product model $y_{i}$. The product models are obtained by a stepwise regression analysis. In this method, the regression starts with an empty model (i.e., no term) and the covariate (e.g., single, quadratic, interaction) is chosen that has the smallest $p$-value when it is the only covariate in the regression model. The $\mathrm{p}$-value of each term tests the null hypothesis that the coefficient of the covariate is equal to zero. A low p-value signifies that the null hypothesis is rejected (the covariate is significant). In order to calculate the p-value, the F-statistic is calculated, that is, the square of the t-statistic of the estimated coefficient of the covariate is compared with the tabulated F-statistic for the same degrees of freedom [20]. In the next steps, covariates are added and removed. At every step, the F-statistic of each covariate is cheeked. The covariate is removed if its F-statistic is less than the user defined "F-to-remove" statistic, and a new covariate is added if its F-statistic is highest among the available covariates and more than the user defined "F-to-enter" statistic. When no covariate is left to enter, and all covariates clear the "Fto-enter" statistic limit, the iteration is stopped, and a final model is obtained. For optimization of objective functions (Eqs. 7-11), the genetic algorithm is used. The genetic algorithm is an evolutionary technique of optimization that is inspired by biological evolution (i.e., natural selection). Like biological evaluation, a group of feasible solutions (population), each represented by a string of numbers (chromosomes), produces new solutions (offspring) through some perturbations. A random change in string (mutation in chromosomes) leads to a new solution with improved objective function (characteristics). The algorithm is applied for predefined number of iterations (generations) or allowed to converge if further improvement in the objective function is less than the desired. The genetic algorithm parameters are set using a mutation rate of 0.075 , a population size of 100 , and a convergence of $10^{-8}$.

\section{Experimental plan}

Experiments were conducted on cylindrical bars of the Ti-6Al-4V alloy. Each bar was initially machined from its raw form to a diameter of $28.5 \mathrm{~mm}$. The material and process details are given in Table 2. Experiments were conducted on a high precision lathe (NH22, HMT). A Dropsa MQL system was used that can digitally control the flow rate by changing stroke frequency. Two independently controlled MQL systems were used to supply the aerosol at the rake and the flank face of the tool. Each MQL system consists of an oil tank, reciprocating pneumatic-controlled piston pump, air pressure regulator, and electronic controller. The stroke volume of the pump could be adjusted manually, by which the quantity of oil injected per stroke of the pump in the supply line can be controlled. Air pressure in the supply line could be regulated through an air pressure regulator. An electronic controller was used to control the stroke frequency of the pneumatic pump (i.e., the number of strokes per second the pneumatic pump would operate). The oil from the pneumatic pump is mixed with the pressurized air and then supplied at the rake and the flank face of the tool. The MQL parameters used for investigation were air pressure, stroke volume, stroke frequency, and oil distribution factor $\left(Q_{d}\right)$. $Q_{d}$ varies between 0 and 1 and refers to the proportion of oil supplied at the rake and flank face. For total oil consumption rate $O_{s}$, the rake and flank faces are supplied with $Q_{d}{ }^{*} O_{s}$ and $\left(1-Q_{d}\right)^{*} O_{s}$ amounts of oil, respectively. In extreme cases, $Q_{d}=0$ represents that no oil is supplied at rake face (i.e., all oil is supplied at flank face), and $Q_{d}=1$ represents that oil is only supplied at rake face. The machining parameters used were cutting speed, feed rate, and depth of cut. In total, seven input parameters were considered for investigation. The output parameters considered for investigation 
Table 2

Material and process details.

\begin{tabular}{|c|c|c|c|c|c|c|}
\hline Machine tool & & & & \multicolumn{3}{|c|}{ High precision Lathe $\mathrm{NH} 22$} \\
\hline \multirow[t]{2}{*}{$\begin{array}{l}\text { Work specimen } \\
\text { Material dimension } \\
\text { Tool holder } \\
\text { Cutting tool insert } \\
\text { Cutting fluid }\end{array}$} & & & & \multicolumn{3}{|c|}{$\begin{array}{l}\text { Ti-6Al-4 V alloy } \\
28.5 \mathrm{~mm} \text { diameter and } 110 \mathrm{~mm} \\
\text { PSSNR } 2525 \mathrm{M} 12 \\
\text { S-grade, TS2500 } \\
\text { LRT } 30 \text { (Drops mfd. MQL fluid) }\end{array}$} \\
\hline & Level & -2 & -1 & 0 & 1 & 2 \\
\hline \multirow[t]{3}{*}{ Machining parameters } & Depth of cut (mm) & 0.5 & 1 & 1.5 & 2 & 2.5 \\
\hline & Cutting speed (m/min) & 49.21 & 63.98 & 75.17 & 83.72 & 127.97 \\
\hline & Feed $(\mathrm{mm} / \mathrm{rev})$ & 0.04 & 0.14 & 0.28 & 0.4 & 0.56 \\
\hline \multirow[t]{4}{*}{ MQL parameters and supply } & Pressure (bar) & 3.5 & 4.5 & 5.5 & 6.5 & 7.5 \\
\hline & Stroke volume $\left(\mathrm{cm}^{3}\right)$ & 0.01 & 0.015 & 0.02 & 0.025 & 0.03 \\
\hline & Stroke frequency $(\mathrm{Hz})$ & 1 & 2 & 3 & 4 & 5 \\
\hline & Oil distribution factor (Qd) & 0 & 0.25 & 0.5 & 0.75 & 1 \\
\hline
\end{tabular}

were specific cutting energy, surface roughness, material removal rate, and oil consumption rate. An L50 orthogonal array was used to conduct the experiments, as shown in Table 3.
The single-point cutting tool was mounted on the piezo-electric based dynamometer to measure the cutting forces that were used to calculate the specific cutting energy. The following relations were

Table 3

L50 experimental design.

\begin{tabular}{|c|c|c|c|c|c|c|c|}
\hline S. No. & Depth of cut (mm) & Speed $(\mathrm{m} / \mathrm{min})$ & Feed $(\mathrm{mm} / \mathrm{rev})$ & Pressure (bar) & Stroke Volume (cc) & Stroke frequency $(\mathrm{Hz})$ & Oil distribution factor $(\mathrm{Qd})$ \\
\hline 1 & 0.5 & 49.21 & 0.04 & 3.5 & 0.010 & 1 & 0.00 \\
\hline 2 & 0.5 & 63.98 & 0.14 & 4.5 & 0.015 & 2 & 0.25 \\
\hline 3 & 0.5 & 75.17 & 0.28 & 5.5 & 0.020 & 3 & 0.50 \\
\hline 4 & 0.5 & 83.72 & 0.40 & 6.5 & 0.025 & 4 & 0.75 \\
\hline 5 & 0.5 & 127.97 & 0.56 & 7.5 & 0.030 & 5 & 1.00 \\
\hline 6 & 1.0 & 49.21 & 0.14 & 5.5 & 0.025 & 5 & 0.00 \\
\hline 7 & 1.0 & 63.98 & 0.28 & 6.5 & 0.030 & 1 & 0.25 \\
\hline 8 & 1.0 & 75.17 & 0.40 & 7.5 & 0.010 & 2 & 0.50 \\
\hline 9 & 1.0 & 83.72 & 0.56 & 3.5 & 0.015 & 3 & 0.75 \\
\hline 10 & 1.0 & 127.97 & 0.04 & 4.5 & 0.020 & 4 & 1.00 \\
\hline 11 & 1.5 & 49.21 & 0.28 & 7.5 & 0.015 & 4 & 0.75 \\
\hline 12 & 1.5 & 63.98 & 0.40 & 3.5 & 0.020 & 5 & 1.00 \\
\hline 13 & 1.5 & 75.17 & 0.56 & 4.5 & 0.025 & 1 & 0.00 \\
\hline 14 & 1.5 & 83.72 & 0.04 & 5.5 & 0.030 & 2 & 0.25 \\
\hline 15 & 1.5 & 127.97 & 0.14 & 6.5 & 0.010 & 3 & 0.50 \\
\hline 16 & 2.0 & 49.21 & 0.40 & 4.5 & 0.030 & 3 & 1.00 \\
\hline 17 & 2.0 & 63.98 & 0.56 & 5.5 & 0.010 & 4 & 0.00 \\
\hline 18 & 2.0 & 75.17 & 0.04 & 6.5 & 0.015 & 5 & 0.25 \\
\hline 19 & 2.0 & 83.72 & 0.14 & 7.5 & 0.02 & 1 & 0.50 \\
\hline 20 & 2.0 & 127.97 & 0.28 & 3.5 & 0.025 & 2 & 0.75 \\
\hline 21 & 2.5 & 49.21 & 0.56 & 6.5 & 0.020 & 2 & 0.75 \\
\hline 22 & 2.5 & 63.98 & 0.04 & 7.5 & 0.025 & 3 & 1.00 \\
\hline 23 & 2.5 & 75.17 & 0.14 & 3.5 & 0.030 & 4 & 0.00 \\
\hline 24 & 2.5 & 83.72 & 0.28 & 4.5 & 0.010 & 5 & 0.25 \\
\hline 25 & 2.5 & 127.97 & 0.40 & 5.5 & 0.015 & 1 & 0.50 \\
\hline 26 & 0.5 & 49.21 & 0.04 & 6.5 & 0.030 & 4 & 0.50 \\
\hline 27 & 0.5 & 63.98 & 0.14 & 7.5 & 0.010 & 5 & 0.75 \\
\hline 28 & 0.5 & 75.17 & 0.28 & 3.5 & 0.015 & 1 & 1.00 \\
\hline 29 & 0.5 & 83.72 & 0.40 & 4.5 & 0.020 & 2 & 0.00 \\
\hline 30 & 0.5 & 127.97 & 0.56 & 5.5 & 0.025 & 3 & 0.25 \\
\hline 31 & 1.0 & 49.21 & 0.14 & 3.5 & 0.020 & 3 & 0.25 \\
\hline 32 & 1.0 & 63.98 & 0.28 & 4.5 & 0.025 & 4 & 0.50 \\
\hline 33 & 1.0 & 75.17 & 0.40 & 5.5 & 0.030 & 5 & 0.75 \\
\hline 34 & 1.0 & 83.72 & 0.56 & 6.5 & 0.010 & 1 & 1.00 \\
\hline 35 & 1.0 & 127.97 & 0.04 & 7.5 & 0.015 & 2 & 0.00 \\
\hline 36 & 1.5 & 49.21 & 0.28 & 5.5 & 0.010 & 2 & 1.00 \\
\hline 37 & 1.5 & 49.21 & 0.28 & 5.5 & 0.010 & 2 & 1.00 \\
\hline 38 & 1.5 & 75.17 & 0.56 & 7.5 & 0.020 & 4 & 0.25 \\
\hline 39 & 1.5 & 83.72 & 0.04 & 3.5 & 0.025 & 5 & 0.50 \\
\hline 40 & 1.5 & 127.97 & 0.14 & 4.5 & 0.030 & 1 & 0.75 \\
\hline 41 & 2.0 & 49.21 & 0.40 & 7.5 & 0.025 & 1 & 0.25 \\
\hline 42 & 2.0 & 63.98 & 0.56 & 3.5 & 0.030 & 2 & 0.50 \\
\hline 43 & 2.0 & 75.17 & 0.04 & 4.5 & 0.010 & 3 & 0.75 \\
\hline 44 & 2.0 & 83.72 & 0.14 & 5.5 & 0.015 & 4 & 1.00 \\
\hline 45 & 2.0 & 127.97 & 0.28 & 6.5 & 0.020 & 5 & 0.00 \\
\hline 46 & 2.5 & 49.21 & 0.56 & 4.5 & 0.015 & 5 & 0.50 \\
\hline 47 & 2.5 & 63.98 & 0.04 & 5.5 & 0.020 & 1 & 0.75 \\
\hline 48 & 2.5 & 75.17 & 0.14 & 6.5 & 0.025 & 2 & 1.00 \\
\hline 49 & 2.5 & 83.72 & 0.28 & 7.5 & 0.030 & 3 & 0.00 \\
\hline 50 & 2.5 & 127.97 & 0.40 & 3.5 & 0.010 & 4 & 0.25 \\
\hline
\end{tabular}


used to calculate the specific cutting energy, material removal rate, and oil consumption rate:

specific cutting energy $=\frac{\text { cutting force }}{\text { feed } \times \text { depth of } c u t}$

Material removal rate $=$ feed $\times$ depth of cut $\times$ cutting speed

Oil consumption rate $=$ Stroke frequency $\times$ stroke volume

Surface roughness was measured using the MarSurf XT20 surface roughness tester. The tool wear $\left(V B_{\max }\right)$ was measured on the flank face. Each experiment was repeated three times, and the average values of the output responses were used for further investigation. Fig. 2 (a, b, c) shows the typical results for the cutting force, surface roughness, and tool wear.

\section{Results and discussion}

\subsection{Parametric effect}

The output results obtained from the L50 experiments are shown in Fig. 3. There exists an interrelation between process responses. The relationship between the material removal rate and specific cutting energy follows the expected trend; that an increase in specific cutting energy leads to a reduction in material removal rate (Fig. 3a). The slower removal rate represents smaller particle size or a thinner chip, which increases the surface area generated during machining, which in turn increases the surface energy. However, a smaller volume of

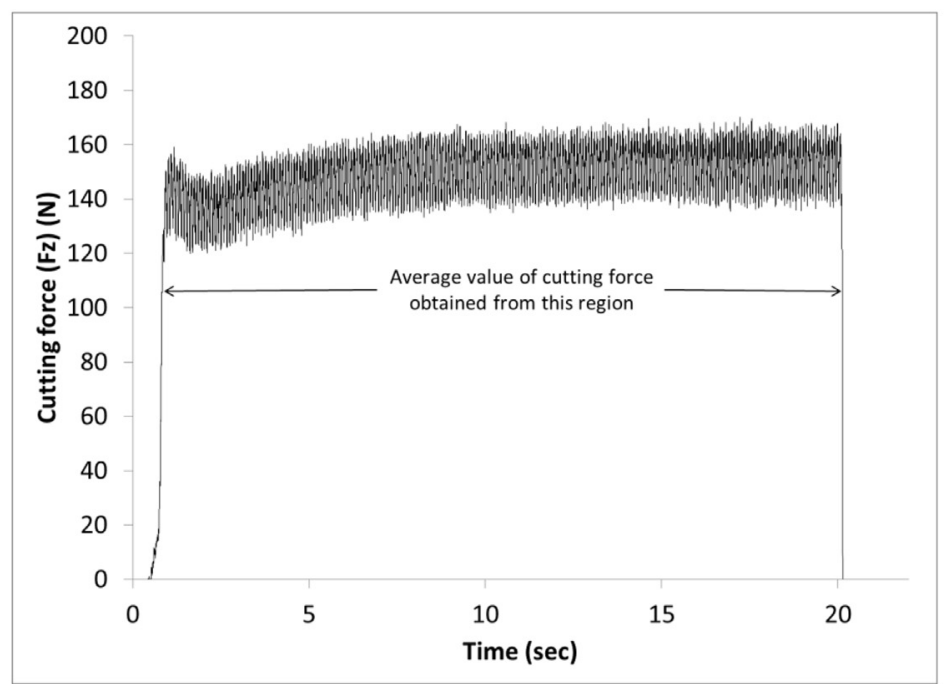

(a)

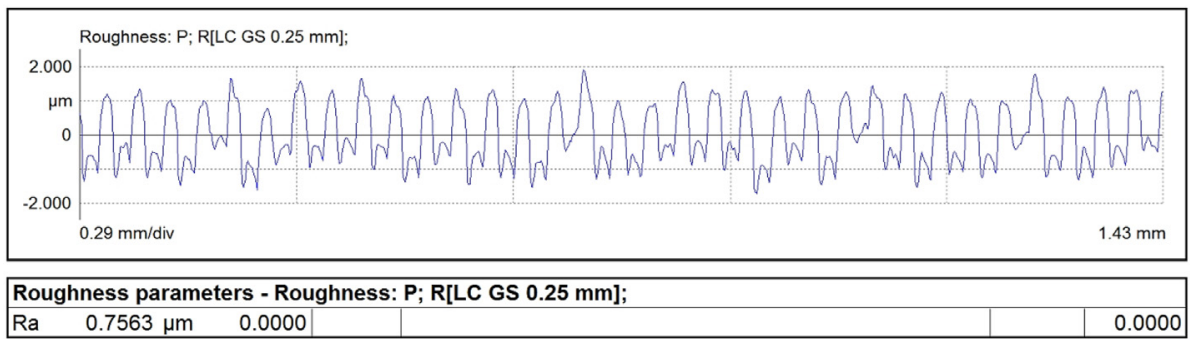

(b)

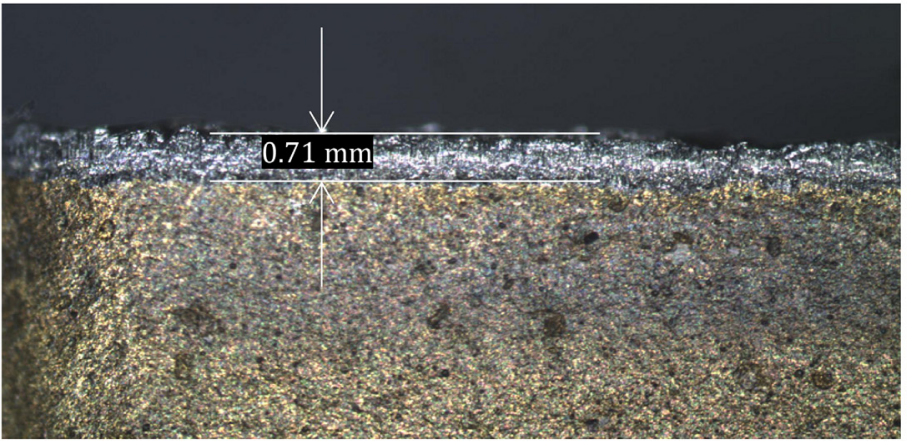

(c)

Fig. 2. Typical experimental results (sample no. 18)

(a) Cutting force

(b) Surface roughness

(c) Tool wear 


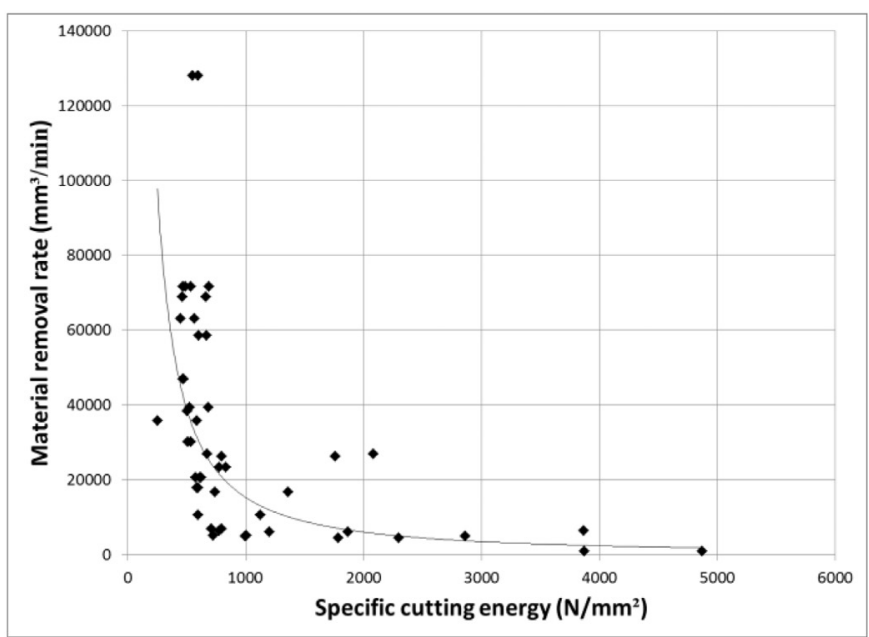

(a)

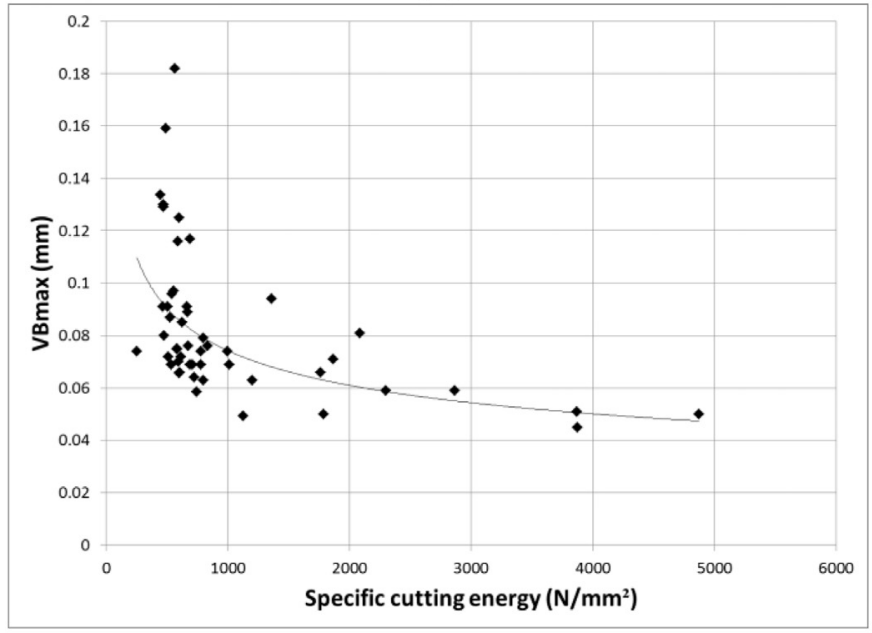

(c)

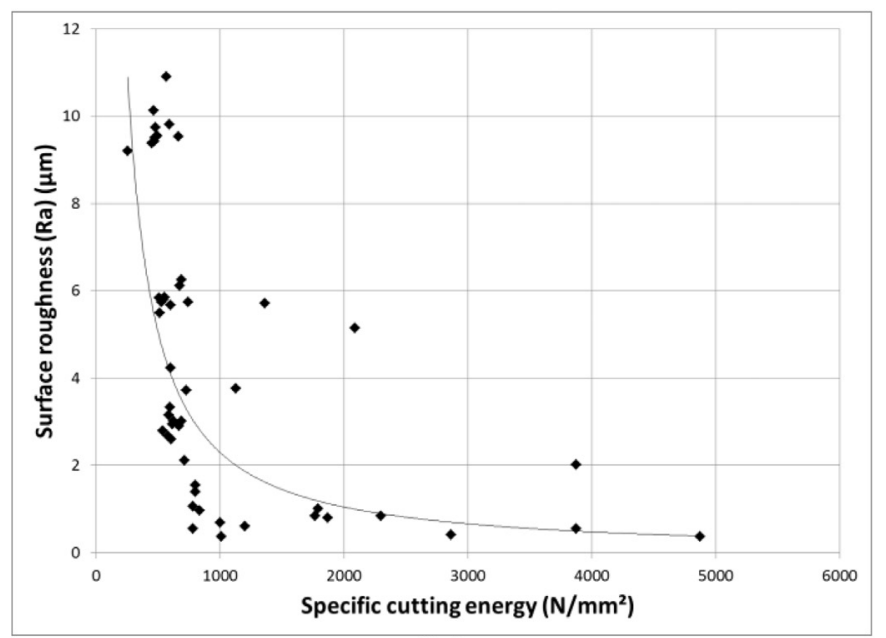

(b)

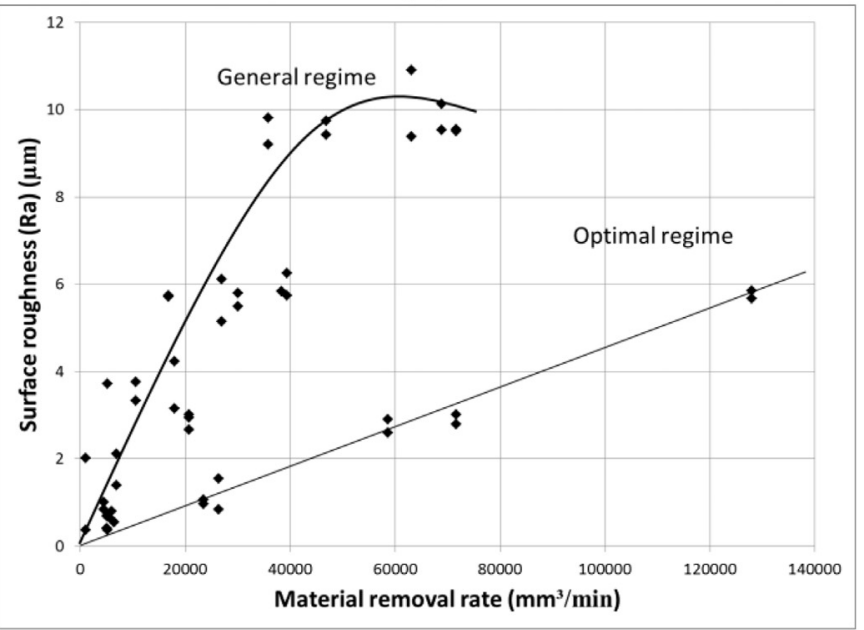

(d)

Fig. 3. Graphical representation of experimental results.

removal generates a finer surface. Thus, a smaller value of surface roughness is associated with larger specific cutting energy (Fig. 3b). The higher specific cutting energy (vis-à-vis, a slower removal rate) was associated with lesser tool wear (Fig. 3c). Fig. 3(d) shows that the surface roughness can be reduced when the material removal rate is kept minimal.

In industrial scenarios, when a higher production rate is needed, the material removal rate must be increased. Hence, a trade-off between surface roughness, tool wear, and material removal rate must be considered. On close examination of Fig. 3(d), there are two regimes, termed as general and optimal. In the optimal regime, a considerably lower surface roughness can be achieved, even at higher material removal rates. This suggests that the different oil application methods, which are achieved by changing the MQL parameters, can significantly influence the outcome of a turning process. This creates a need for systematically optimizing the process parameters to achieve the desired output. The process responses are associated with individual sets of process inputs that need not be the same. The regression models described below depict this dissimilarity.

\subsection{Regression model}

The regression models were obtained using a stepwise regression method, wherein insignificant covariates (parameters or their interactions) are eliminated. The regression models of surface roughness, cutting force, and tool wear are given in Eqs. 14-16, respectively. Fitting a model with a cutting force (Fz) and using Eq. 11 to compute the specific cutting energy gives a better fit compared to converting Fz to a specific cutting energy and then fitting a model to the specific cutting energy.

$$
\begin{aligned}
& R \boldsymbol{R}(\boldsymbol{\mu m})= 0.253 \times P+108 \times V+0.305 \times F-3.84 \times Q d-0.614 \\
& \times d^{2}+0.000342 \times C^{2}+24.51 \times f^{2}-0.0968 \times P^{2} \\
& 3692 \times V^{2}+0.2673 \times d \times P-0.0638 \times C \\
& \times f-2.242 \times C \times V+0.0311 \times C \times Q_{d}+0.870 \times f \\
& \times P+0.0877 \times f \times F+0.325 \times P \times Q_{d}-28.4 \times V \\
& \times F \\
& F z(N)=14.08 \times d^{2}+396.6 \times d \times f+2265 \times d \times V \\
& V B \max (\boldsymbol{m m})= 0.08858 \times d+0.0643 \times Q d-0.02113 \times d^{2} \\
&+0.1967 \times f^{2}-0.00555 \times d \times F+0.000490 \times C \\
& \times f-0.00675 \times C \times F-0.0909 \times f \times Q_{d} \\
&+0.001225 \times P \times F-0.01067 \times P \times Q_{d}
\end{aligned}
$$

where $d$ is the depth of cut ( $\mathrm{mm}), C$ is cutting speed $(\mathrm{m} / \mathrm{min}), f$ is feed $(\mathrm{mm} / \mathrm{rev}), P$ is pressure (bar), $V$ is stroke volume (cc), $F$ is stroke frequency $(\mathrm{Hz})$, and $Q_{d}$ is the oil distribution factor. Fig. 4 shows that the predicted values are in good agreement with the experimental results. The models were validated using experimental data that are different from that used to develop the models. The coefficients of determination $\left(R^{2}\right)$ of the regressions (Eqs. 14-16) are 0.98, 0.94, and 0.98, respectively, which demonstrate good fits. Not all the covariates appearing 


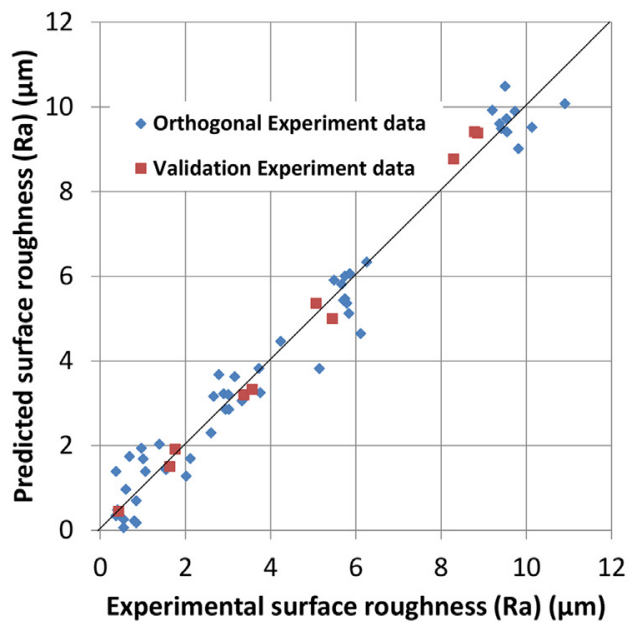

(a)

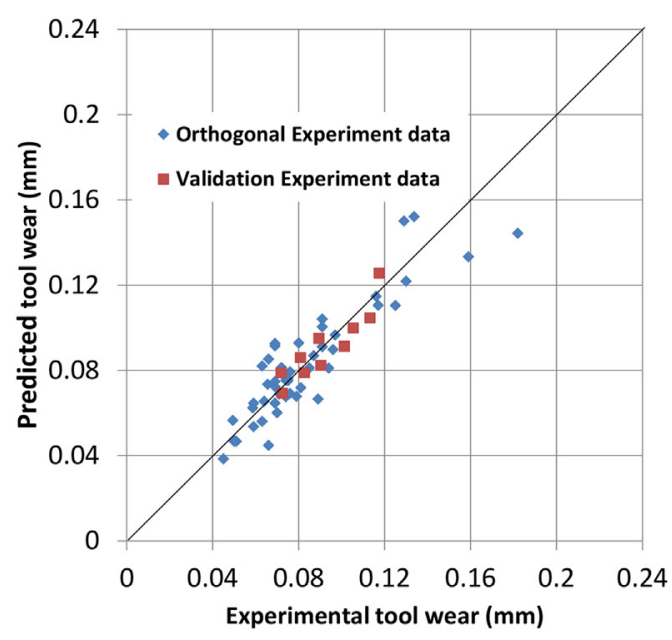

(c)

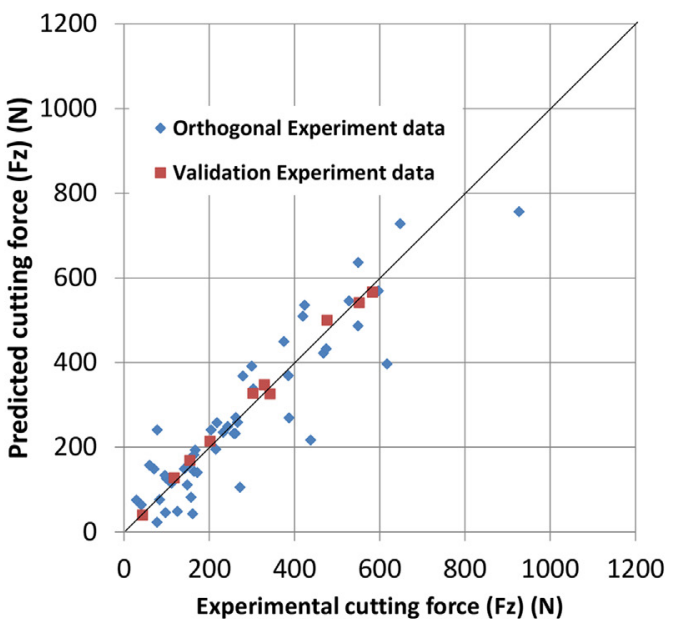

(b)

Fig. 4. Comparison of actual and predicted data. (a) Surface roughness. (b)Cutting force. (c) Tool wear.

in the three regression models are identical. Different responses are affected by different sets of parameters, which leads to complex multivariable relations that affect the optimization objectives that are functions of one or more process outcomes. The complexity in relations reflects on the optimization outcome, as discussed next.

\subsection{Process optimization}

The results of the various process optimizations are shown in Fig. 5a and $\mathrm{b}$ for one-side-constrained and both-sides-constrained roughness, respectively. The value of sub-index between 0 and 1 shows the worst and best possible situations for an individual response, respectively.

Fig. 5a shows that optimization with an objective of maximizing quality results in a surface roughness sub-index close to 1 (i.e., minimum surface roughness). This happens at the cost of the material removal rate, which is severely affected, along with moderate tool wear, oil consumption rate, and specific cutting energy. The values for the different process outcomes are shown in Table 4. However, the tool wear, oil consumption rate, and specific cutting energy are near optimal when the objective of optimization is environmental. However, this happens at the cost of the material removal rate and surface roughness that have sub-indices that are close to zero. With production rate as an objective, oil and specific energy are consumed more, and the surface produce is relatively rough, as indicated by their close to zero sub-indices. If all the objectives are simultaneously optimized, a balanced solution can be achieved, wherein moderate surface finish and material removal rate can be obtained with less consumption of tool, oil, and energy. Further pushing optimization towards the product specification by constraining surface roughness to a maximum of $2 \mu \mathrm{m}$ leads to a bettering of the surface roughness with only a small reduction in the material removal rate and increase in tool wear (Fig. 5b); however, oil and energy consumption can be kept minimal, as shown in Table 4. It is important to note that the oil consumption rate in the all-inclusive optimization is like the minimum obtained during environmental optimization. The production rate obtained with the all-inclusive optimization is secondbest, below that obtained when solely production is considered. In this way, all-inclusive optimization is an acceptable solution, wherein a balance of several objectives can be achieved.

\subsection{Parameter selection strategies}

The findings presented here provide important insights into parameter selection for the MQL machining, particularly the introduction of an oil distribution factor. For better quality (i.e., surface roughness), the oil should be distributed between the rake and flank faces such that between 15 and $20 \%$ is supplied at the rake face (i.e., $Q_{d}=0.16$ ). When cutting speed and feed rates are kept low, such judicious use of oil provides a good surface finish (Table 5). From an environmental perspective, it would be more beneficial if oil is supplied totally at the rake face $\left(Q_{d}=1\right)$, where the maximum heat is generated. This prevents overconsumption of energy in cutting, with the minimum possible consumption of oil. However, from environmental perspectives, the cutting 


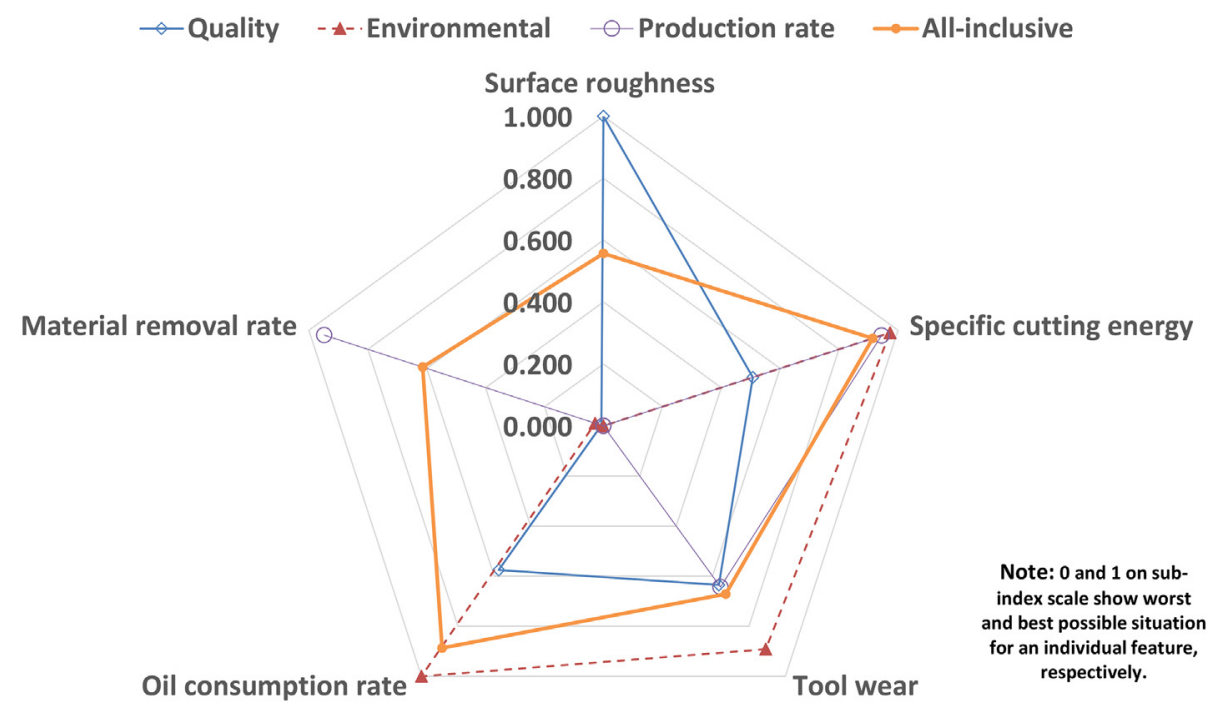

(a)

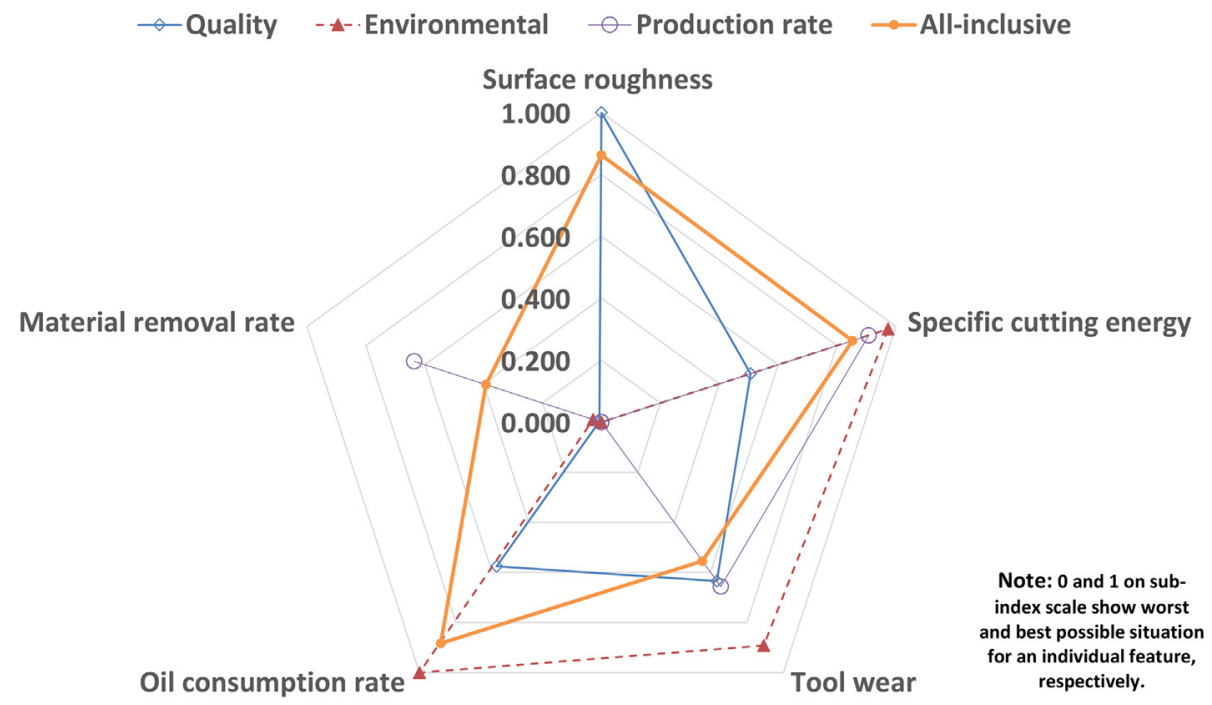

(b)

Fig. 5. Optimization results

(d) One side constrained roughness for rough cut $\left(R_{a} \geq 0.0321 \frac{f_{\min }^{2}}{r}\right)$

(e) (b) Both side constrained roughness ( $0.0321 \frac{f_{\frac{\min }{2}}}{r} \leq R_{a} \leq 2 \mu m$.)

speed and depth of cut need to be kept at a minimum (Table 5). This severely hampers the production rate. The production rate, without any constraint on surface roughness, can be maximized by pushing the cutting speed, feed rate, and depth of cut to their maximum, and supplying oil at the rake face $\left(Q_{d}=1\right)$. However, when the production rate is constrained by the maximum surface roughness, the feed rate needs to be kept moderate, and oil should be supplied at low pressure with $\mathrm{Qd}=0.05$ (i.e., $95 \%$ of oil at the flank face, thus reducing tool wear so that the production rate is not affected by delay due to tool change). It should also be noted that the maximum production rate comes at a cost of high oil consumption rate.

For the all-inclusive aspect, the objective can be best achieved when the cutting speed and depth of cut are at their maximum, and the feed rate and oil consumption rate are controlled. Higher cutting speeds and depths of cut help to produce a higher production rate and controlling the feed rate helps to attain a good surface finish. Controlling the oil consumption rate is required from an environmental perspective. The oil can be supplied entirely to the rake face $\left(Q_{d}=1\right)$ if there is no constraint on the maximum surface roughness; however, if the maximum surface roughness is limited, the feed rate needs to be further reduced, and more oil should be supplied at the flank face $\left(Q_{d}=0.12\right.$, i.e. $88 \%$ at the flank face). Hence, in short, it can be seen that the multiple nozzle position is useful when quality is considered and also for the cases of production rate and all-inclusive under constrained surface roughness conditions.

The Table 5 elucidate the role played by the multiple jets. The jet at the flank face is essential to have desired finish as it can be seen from the results of the rough cut $(\mathrm{Qd}=0.16)$. Without the need of surface finish, the total oil can be supplied from the jet at the rack face $\left[Q_{d}=\right.$ 1 (entire oil supplied on rack face) when purely environmental and production rate are considered]. When quality is desired, which is an essential part of a finish cut (i.e., roughness constrained from both sides) both 
Table 4

Optimum results.

\begin{tabular}{|c|c|c|c|c|c|c|}
\hline \multirow[t]{2}{*}{ Response } & \multirow[t]{2}{*}{ Individual minimum } & \multirow[t]{2}{*}{ Individual maximum } & \multicolumn{4}{|c|}{ Optimization objectives } \\
\hline & & & Quality & Environmental & Production rate & All-inclusive \\
\hline \multicolumn{7}{|c|}{ One side constrained roughness for rough cut $\left(\boldsymbol{R}_{\boldsymbol{a}} \geq \mathbf{0 . 0 3 2 1} \frac{f_{\min }{ }^{2}}{r}\right)$} \\
\hline Surface roughness (Ra) & 0.06 & 14.17 & 0.06 & 1.16 & 9.52 & 5.92 \\
\hline Specific cutting energy (S) & $4.50 \times 10^{2}$ & $2.98 \times 10^{3}$ & $1.69 \times 10^{3}$ & $5.17 \times 10^{2}$ & $5.89 \times 10^{2}$ & $6.66 \times 10^{2}$ \\
\hline Tool wear $(\mathrm{T})$ & 0.00 & 0.18 & 0.07 & 0.02 & 0.07 & 0.06 \\
\hline Oil consumption rate (Os) & 0.01 & 0.15 & 0.07 & 0.01 & 0.15 & 0.03 \\
\hline Material removal rate $(\mathrm{M})$ & $9.84 \times 10^{2}$ & $1.81 \times 10^{5}$ & $2.19 \times 10^{3}$ & $6.06 \times 10^{3}$ & $1.71 \times 10^{5}$ & $1.11 \times 10^{5}$ \\
\hline \multicolumn{7}{|c|}{ Both side constrained roughness $\left(0.0321 \frac{f_{\min }}{r} \leq R_{a} \leq 2 \mu m\right)$} \\
\hline Surface roughness $(\mathrm{Ra})$ in & 0.06 & 14.17 & 0.06 & 1.16 & 2.00 & 2.00 \\
\hline Specific cutting energy (S) & $4.50 \times 10^{2}$ & $2.98 \times 10^{3}$ & $1.70 \times 10^{3}$ & $5.17 \times 10^{2}$ & $6.83 \times 10^{2}$ & $8.22 \times 10^{2}$ \\
\hline Tool wear $(\mathrm{T})$ & 0.00 & 0.18 & 0.07 & 0.02 & 0.06 & 0.08 \\
\hline Oil consumption rate $(\mathrm{Oc})$ & 0.01 & 0.15 & 0.07 & 0.01 & 0.15 & 0.03 \\
\hline Material removal rate $(\mathrm{M})$ & $9.84 \times 10^{2}$ & $1.81 \times 10^{5}$ & $2.19 \times 10^{3}$ & $6.06 \times 10^{3}$ & $1.15 \times 10^{5}$ & $7.14 \times 10^{4}$ \\
\hline
\end{tabular}

the jets are required as oil supplied at flank face ensures the surface roughness.

The results of the optimization exercise give insight into MQL machining from different perspectives that might be useful on the shop floor. It is important to note that no such comprehensive investigation of MQL has been previously reported. The results of this investigation will help to develop a better understanding of the role of oil distribution at the flank and rake face, which is important in the successful process design for MQL machining of a variety of materials. Moreover, the introduction of an oil distribution factor adds a predictor to the process model, which helps to capture process response with greater accuracy and, thereby, improves the possibility of attaining optimal conditions with different sets of objective and constraints.

\subsection{Enhancement in sustainability}

An appropriate use of modeling and optimization helps quantify and thereby enhance sustainability. An analysis of the amount of oil consumed per unit material removal, - calculated for various objectives from the data given in Table 3 - gives a conclusive evidence of improvement in sustainability. In both the cases of rough and finish cut, minimum oil per unit material removal is obtained with the parameters obtained by all-inclusive optimization, i.e., all-inclusive optimization for rough cut leads to a reduction in oil consumption by 6 and 3 times when compared with purely environmental or production rate, respectively. The same reduction in finish cut is 4 and 3 times, respectively. Purely environmental aspect in optimization though minimizes the absolute consumption of the oil, but so obtained parameters more severely reduce the material removal rate that leads to increase in use of oil per unit materials processed. The results of the investigation present a way to improve the sustainability of the machining process, wherein, a judicious distribution of oil at the rake and flank face reduces the unnecessary wastage of oil by systematically channelizing only the required quantity at the proper location depending on the final objective.

\section{Conclusions}

MQL machining is collectively optimized for quality, production, and environmental perspectives. An experimental study of the effect of machining and MQL parameters was made to understand the effects on surface roughness, specific cutting energy, tool wear, oil consumption rate, and material removal rate. A new parameter - an oil distribution factor that quantifies the proportion of oil at the rake and flank face was introduced during the optimization. The effects were quantified by developing process models. The following are the major conclusions that are drawn from the present work:

1. The MQL is a multi-parameter operation that needs precise control over the oil consumption rate parameters, such as oil quantity and air pressure in an aerosol. Attention must be given to oil quantities at the rake and flank face. This investigation introduces quantitative assessment of the effect of the proportion of oil at the rake and the flank face on surface roughness, specific cutting energy, and tool wear.

2. The process outcomes are distinct functions of process inputs; surface roughness and tool wear are affected by all the input process parameters, while the specific cutting energy is a function of mainly feed, depth of cut, and oil consumption rate.

3. A good surface finish can be obtained by supplying a large amount of oil at the flank face at low cutting speed and feed rate, and a minimum depth of cut; however, this hampers the material removal rate. Similarly, environmental objectives can be obtained at the cost of material removal rate. Optimizing production rate by improving the material removal rate leads to a poor surface finish, even when the oil consumption rate is maximized.

Table 5

Optimized process parameters.

\begin{tabular}{|c|c|c|c|c|c|c|c|}
\hline & Speed $(\mathrm{m} / \mathrm{min})$ & Feed $(\mathrm{mm} / \mathrm{rev})$ & Depth of cut (mm) & Pressure (bar) & Stroke volume (cc) & Stroke frequency $(\mathrm{Hz})$ & Oil distribution factor $\left(Q_{d}\right)$ \\
\hline \multicolumn{8}{|c|}{ One side constrained roughness for rough cut $\frac{\left(\boldsymbol{R}_{a} \geq \mathbf{0 . 0 3 2 1 f _ { \operatorname { m i n } }}\right.}{\mathbf{r})}$} \\
\hline Quality & 61.12 & 0.04 & 0.90 & 6.45 & 0.02 & 4.00 & 0.16 \\
\hline Environmental & 49.21 & 0.25 & 0.50 & 7.50 & 0.01 & 1.00 & 1.00 \\
\hline Production rate & 127.97 & 0.54 & 2.50 & 7.50 & 0.03 & 5.00 & 1.00 \\
\hline All-inclusive & 127.97 & 0.35 & 2.50 & 7.50 & 0.03 & 1.00 & 1.00 \\
\hline \multicolumn{8}{|c|}{ Both side constrained roughness $\frac{\left(\mathbf{0 . 0 3 2 1 f _ { \operatorname { m i n } }}{ }^{2}\right.}{\left.r \leq R_{a} \leq 2 \mu m\right)}$} \\
\hline Quality & 61.13 & 0.04 & 0.90 & 6.45 & 0.02 & 4.00 & 0.16 \\
\hline Environmental & 49.21 & 0.25 & 0.50 & 7.50 & 0.01 & 1.00 & 1.00 \\
\hline Production rate & 127.97 & 0.36 & 2.50 & 3.50 & 0.03 & 5.00 & 0.05 \\
\hline All-inclusive & 127.97 & 0.22 & 2.50 & 7.50 & 0.03 & 1.00 & 0.12 \\
\hline
\end{tabular}


4. The comprehensive, simultaneous optimization, that includes quality, environmental, and production, offers a reasonable balance. The inclusion of MQL parameters in modeling increases the number of process parameters, which increases the possibility of obtaining a feasible and optimal solution.

5. Parameters should be separately selected for rough and finish cuts. The rough-cut offers relaxation in quality that allows improvement in environmental performance. The judicious distribution of oil inbetween the rake and flank face offer options for the end-user to adjust the process when operating with various objectives and under different constraints.

\section{References}

[1] N. Banerjee, A. Sharma, Multi-point injection minimum quantity lubrication machining, Materials Science Forum, vol. 830, Trans Tech Publications 2015, pp. 108-111.

[2] B. Chirita, G. Mustea, G. Brabie, A statistical analysis applied for optimal cooling system selection and for a superior surface quality of machined magnesium alloy parts, Proc. Inst. Mech. Eng. B J. Eng. Manuf. 229 (3) (2014) 392-408.

[3] B. Davoodi, A.H. Tazehkandi, Experimental investigation and optimization of cutting parameters in dry and wet machining of aluminum alloy 5083 in order to remove cutting fluid, J. Clean. Prod. 68 (2014) 234-242.

[4] S. Debnath, M.M. Reddy, Q.S. Yi, Environmental friendly cutting fluids and cooling techniques in machining: a review, J. Clean. Prod. 83 (2014) 33-47.

[5] J.S. Dureja, R. Singh, T. Singh, P. Singh, M. Dogra, M.S. Bhatti, Performance evaluation of coated carbide tool in machining of stainless steel (AISI 202) under minimum quantity lubrication (MQL), Int. J. Precis. Eng. Manuf. Green Technol. 2 (2) (2015) 123-129.

[6] D. Fratila, C. Caizar, Application of Taguchi method to selection of optimal lubrication and cutting conditions in face milling of AlMg 3, J. Clean. Prod. 19 (6) (2011) 640-645.

[7] V.N. Gaitonde, S.R. Karnik, J.P. Davim, Selection of optimal MQL and cutting conditions for enhancing machinability in turning of brass, J. Mater. Process. Technol. 204 (1) (2008) 459-464.

[8] S. Ghosh, P.V. Rao, Application of sustainable techniques in metal cutting for enhanced machinability: a review, J. Clean. Prod. 100 (2015) 17-34.

[9] F. Jiang, J. Li, L. Yan, J. Sun, S. Zhang, Optimizing end-milling parameters for surface roughness under different cooling/lubrication conditions, Int. J. Adv. Manuf. Technol. 51 (9) (2010) 841-851.

[10] Z. Jiang, F. Zhou, H. Zhang, Y. Wang, J.W. Sutherland, Optimization of machining parameters considering minimum cutting fluid consumption, J. Clean. Prod. 108 (2015) 183-191.

[11] E. Kuram, B. Ozcelik, M. Bayramoglu, E. Demirbas, B.T. Simsek, Optimization of cutting fluids and cutting parameters during end milling by using D-optimal design of experiments, J. Clean. Prod. 42 (2013) 159-166.
[12] Z. Liu, J. Xu, S. Han, M. Chen, A coupling method of response surfaces (CRSM) for cutting parameters optimization in machining titanium alloy under minimum quantity lubrication (MQL) condition, Int. J. Precis. Eng. Manuf. 14 (5) (2013) 693-702.

[13] J.S. Nam, D.H. Kim, H. Chung, S.W. Lee, Optimization of environmentally benign micro-drilling process with nanofluid minimum quantity lubrication using response surface methodology and genetic algorithm, J. Clean. Prod. 102 (2015) 428-436.

[14] F. Pusavec, A. Deshpande, S. Yang, R. M'Saoubi, J. Kopac, O.W. Dillon, I.S. Jawahir, Sustainable machining of high temperature nickel alloy-Inconel 718: part 1-predictive performance models, J. Clean. Prod. 81 (2014) 255-269.

[15] F. Pusavec, A. Deshpande, S. Yang, R. M'Saoubi, J. Kopac, O.W. Dillon, I.S. Jawahir, Sustainable machining of high temperature nickel alloy-Inconel 718: part 2-chip breakability and optimization, J. Clean. Prod. 87 (2015) 941-952.

[16] F. Rabiei, A.R. Rahimi, M.J. Hadad, M. Ashrafijou, Performance improvement of minimum quantity lubrication (MQL) technique in surface grinding by modeling and optimization, J. Clean. Prod. 86 (2015) 447-460.

[17] A. Saini, S. Dhiman, R. Sharma, S. Setia, Experimental estimation and optimization of process parameters under minimum quantity lubrication and dry turning of AISI4340 with different carbide inserts, J. Mech. Sci. Technol. 28 (6) (2014) 2307-2318

[18] M. Sarıkaya, A. Güllü, Taguchi design and response surface methodology based analysis of machining parameters in CNC turning under MQL, J. Clean. Prod. 65 (2014) 604-616.

[19] M. Sarıkaya, A. Güllü, Multi-response optimization of minimum quantity lubrication parameters using Taguchi-based grey relational analysis in turning of difficult-tocut alloy Haynes 25, J. Clean. Prod. 91 (2015) 347-357.

[20] A. Sharma, N. Arora, B.K. Mishra, Statistical modeling of deposition rate in twin-wire submerged arc welding, Proc. Inst. Mech. Eng. B J. Eng. Manuf. 223 (7) (2009) 851-863.

[21] A. Sharma, D.K. Verma, N. Arora, A scheme of comprehensive assessment of weld bead geometry, Int. J. Adv. Manuf. Technol. (2015) 1-9.

[22] A. Sharma, F. Zhao, J.W. Sutherland, Econological scheduling of a manufacturing enterprise operating under a time-of-use electricity tariff, J. Clean. Prod. 108 (2015) 256-270.

[23] V.S. Sharma, G. Singh, K. Sørby, A review on minimum quantity lubrication for machining processes, Mater. Manuf. Process. 30 (8) (2015) 935-953.

[24] Y. Shokoohi, E. Khosrojerdi, B.R. Shiadhi, Machining and ecological effects of a new developed cutting fluid in combination with different cooling techniques on turning operation, J. Clean. Prod. 94 (2015) 330-339.

[25] K. Simunovic, G. Simunovic, T. Saric, Single and multiple goal optimization of structural steel face milling process considering different methods of cooling/lubricating, J. Clean. Prod. 94 (2015) 321-329.

[26] P.K. Swamee, A. Tyagi, Describing water quality with aggregate index, J. Environ. Eng. 126 (5) (2000) 451-455.

[27] E. Vazquez, J. Gomar, J. Ciurana, C.A. Rodríguez, Analyzing effects of cooling and lubrication conditions in micromilling of Ti6Al4V, J. Clean. Prod. 87 (2015) 906-913.

[28] Y. Zhang, P. Zou, B. Li, S. Liang, Study on optimized principles of process parameters for environmentally friendly machining austenitic stainless steel with high efficiency and little energy consumption, Int. J. Adv. Manuf. Technol. 79 (1-4) (2015) 89-99. 